children with leukemia and $1(11.1 \%)$ of a patient with a solid tumor.

The median vitamin $\mathrm{D}$ supply in children from 0 to 3 years old was 16.6 [9.7-21.7] $\mathrm{ng} / \mathrm{ml}$, from 4 to 10 years old - 19.8 [14.7-24.8] ng/ml, from 11 to 18 years old - 16.8 [10.5-17.2] ng/ml. Vitamin D deficiency (less than $20 \mathrm{ng} / \mathrm{ml}$ ) was detected in $6(54.6 \%)$ children under 4 years old, in 8 (50.0\%) children from 4-10 years old and 7 (77.8\%) adolescents of 11 years old and older $(\mathrm{p}<0.05)$; insufficiency with the level from 20 to $30 \mathrm{ng} / \mathrm{ml}$ was detected in $3(27.3 \%), 6$ $(37.5 \%)$ and $1(11.1 \%)$ children, and the level of more than $30 \mathrm{ng} / \mathrm{ml}$ was found in $2(18.1 \%), 2(12.5 \%)$ and $1(11.1 \%)$ children, respectively.

Conclusions in the south of Russia, the majority $(86.0 \%)$ of children and adolescents with cancer have a $25(\mathrm{OH})$ D level of less than $30 \mathrm{ng} / \mathrm{ml}$. Level of $25(\mathrm{OH})$ D did not significantly depend on the type of cancer. Adolescents with cancer are at risk for vitamin D deficiency (less than $20 \mathrm{ng} / \mathrm{ml}$ ).

\section{INTEGRATING SAFFRON METABOLOMICS INTO THE TREATMENT OF PEDIATRIC CANCERS}

Kyriaki Hatziagapiou*, Olti Nikola, Eleni Kakouri, George Lambrou, Eleni Koniari, Christina Kanaka-Gantenbein, Petros Tarantilis. National and Kapodistrian University of Athens, First Department of Pediatrics, Choremeio Research Laboratory, 'Aghia Sophia' Children's Hospital, Athens, Greece

\subsection{6/archdischild-2021-europaediatrics.315}

Natural plant extracts are an important source of antitumor agents, and still provide promising approaches for discovering new drugs. Crocus sativus (saffron) is endowed with anticancer, differentiating, antioxidant and genoprotective properties. Its pharmacological properties are attributed to biologically active substances, crocins (CRCs) which are hydrophilic carotenoids. They are glycosy-esters of the amphiphilic natural carotenoid crocetin (CRT), which exhibits extensive distribution and penetration through lipid bilayers. The hemisynthetic derivate dimethylcrocetin (DMCRT) is similar to CRT and is soluble in many organic solvents. With regards to safety, saffron and its constituents are considered practically non-toxic substances. The current research aims to study the in vitro cytotoxic effect of the natural carotenoids CRCs and DMCRT on a medulloblastoma cell line.

CRCs are diluted to nuclease and protease free water and DMCRT to $10 \%$ DMSO.

For the biological assays TE-671 medulloblastoma cells are incubated in 96-well plates at a range of concentrations of CRCs $(0.18-22.85 \mathrm{mg} / \mathrm{ml})$ and DMCRT $(0.18-11.43 \mathrm{mg} / \mathrm{ml})$ for 24, 48 and 72 hours. Analysis of cell viability is performed with Alamar Blue and MTT viability assays.

CRCs manifest a cytotoxic effect in a dose and timedependent manner $(p<0.001$ for exposed cells to any concentration at 24, 48 and 72 hours versus cells not exposed); as their concentration increases, cell viability is reduced for all time points. For the same concentration, as the time of exposure increases, the inhibitory effect is increased. The antiproliferative effect of DMCRT is less pronounced, observed only at concentrations higher than $5.71 \mathrm{mg} / \mathrm{ml}$ at 24 and 48 hours and higher than

$1.43 \mathrm{mg} / \mathrm{ml}$ at 72 hours, whereas for lower concentrations the effect is not statistically significant. IC50 values for each time point are calculated as $3.230,2.14$ and $1.72 \mathrm{mg} / \mathrm{ml}$ for
CRCs and 5.9, 5.6 and $3.712 \mathrm{mg} / \mathrm{ml}$ for DMCRT at 24, 48, and 72 hours, respectively.

The results of our study could afford the basis of research, regarding the use of natural carotenoids as an alternative solution to the toxicity of retinoids, especially for the vulnerable pediatric population and during pregnancy, while retaining the anticancer properties of retinoids.

Acknowledgements The research is co-financed through the Program 'Support for researchers with an emphasis on young researchers-cycle B ' (MIS 5048464) AND The Foundation for Education and European Culture (IPEP).

\section{INTEGRATING NON PSYCHOACTIVE PHYTOCANNABINOIDS AND THEIR CYCLODEXTRIN INCLUSION COMPLEXES INTO THE TREATMENT OF NEUROBLASTOMA}

Kyriaki Hatziagapiou*, Konstantinos Bethanis, Olti Nikola, Elias Christoforides, Eleni Koniari, Eleni Kakouri, George Lambrou, Christina Kanaka-Gantenbein. National and Kapodistrian University of Athens, First Department of Pediatrics, Choremeio Research Laboratory, 'Aghia Sophia' Children's Hospital, Athens, Greece

\subsection{6/archdischild-2021-europaediatrics.316}

The non-psychotropic cannabidiol (CBD), deriving from Cannabis sativa is endowed with anticancer, antioxidant and genoprotective properties, which along with its safe profile suggest it as a promising approach in cancer therapy. The low solubility of CBD hampers its therapeutic potential.

Cyclodextrins (CDs) are cyclic oligosaccharides used in pharmaceutical industry to incorporate apolar molecules inside their hydrophobic cavity, increasing their stability, water solubility and bioavailability.

CBD-inclusion complexes with CDs are a good nanomedicine-based formulation strategy to improve CBD's properties. The current research aims to study the potential cytotoxic effect of CBD and CBD-CDs complexes CBD-RMßCD (randomly methylated $\beta$-cyclodextrin) and CBD-HP $\beta C D$ (hydroxypropyl-b-CD) on neuroblastoma cells.

CBD is diluted in 10\% DMSO and CBD/CDs solutions are prepared by mixing solid $\mathrm{CBD}$, solid $\mathrm{CDs}$ and $\mathrm{dH} 2 \mathrm{O}$. Phase solubility studies are conducted to determine improvement in CBD's solubility from CDs' addition of. For the biological assays SH-SY5Y and BE(2)-M17 neuroblastoma cells are incubated at a range of concentrations $(0,03125-4 \mathrm{mg} / \mathrm{ml})$ of CBD, CBD-RM $\beta C D$, CBD-HP $\beta C D, R M \beta C D$ and $H P \beta C D$ for 24, 48 and 72 hours. Analysis of cell viability is performed with Alamar Blue viability assay.

CBD's solubility is enhanced in the presence of both CDs. $\mathrm{CBD}$ and all $\mathrm{CBD} / \mathrm{CD}$ s exert significant cytotoxicity in a dose and time-dependent manner; as their concentration and time of exposure increase, cell viability is reduced. The cytotoxic effect is more pronounced in cells exposed to CBD-HP $\beta C D$ for all concentrations and time-points. RM $\beta C D$ and HPßCD at the highest concentration of $4 \mathrm{mg} / \mathrm{ml}$ exert antitumor action per se. IC50 values are calculated as $0.29,0.21,0.06$ $\mathrm{mg} / \mathrm{ml}$ for CBD, $0.046,0.035,0.03 \mathrm{mg} / \mathrm{ml}$ for CBD-RM $\beta C D$, and $0.029,0.023,0.021 \mathrm{mg} / \mathrm{ml}$ for CBD-HPßCD at 24, 48, and 72 hours, respectively for SHSY5Y cells. For BE(2)-M17 cells IC50 values are $0.3,0.27,0.19 \mathrm{mg} / \mathrm{ml}$ for CBD, 0.1655, $0.1644,0.1534 \mathrm{mg} / \mathrm{ml}$ for CBD-RMßCD, and 0.1086 , $0.1020,0.071$ for CBD-HPßCD at 24, 48, and 72 hours, respectively. 
The results of our study could afford the basis of research regarding the use of natural products and their inclusion complexes as anticancer agents and the shift to targeted therapy with higher efficacy and limited toxicity.

Acknowledgements This Research Project is co-financed by Greece and EU (European Social Fund) through the Operational Program «Human Resources Development, Education and Lifelong Learning 2014-2020» and the Program titled 'Support for Post-doctoral Researchers- cycle B' (MIS 5033021), implemented by IKY (State Scholarships Foundation).

\section{L-ASPARAGINASE ACTIVITY MONITORING IN PAEDIATRIC HEMATOLOGICAL CANCER PATIENTS - CROATIAN EXPERIENCES}

Jasna Lenicek Krleza, Ana Katusic Bojanac*, D Buljan, Izabela Kranjcec, Višnja Armanda, Gordana Jakovljevic. Department of Medical Biology, University of Zagreb, School of Medicine, Zagreb, Croatia; Centre of Excellence for Reproductive and Regenerative Medicine, University of Zagreb School of Medicine, Zagreb, Croatia

\subsection{6/archdischild-2021-europaediatrics.317}

L-asparaginase has been an essential component of paediatricbased multiagent therapy for children diagnosed with haematological cancer.

Drug's effect is based on depletion of asparagine in the circulatory system thus depriving unmatured malignant cells of amino acid. However, some children are faced with silent inactivation or, in worst cases, an allergic reaction to the drug and is recommended to monitor drug activity levels in order to detect these patients and modify the therapy. We had set up the first laboratory for asparaginase-activity testing in Croatia at the Department of Laboratory diagnostics, Children's Hospital Zagreb. Our aim is to present the first experiences in asparaginase monitoring from March 2018 till October 2020 from the 2 pediatric centers (Zagreb and Split).

Children between 1 and 18 years old with diagnosed pediatric acute lymphoblastic leukemia (ALL) or lymphoma (NHL) were included in the prospective L-asparaginase study. Blood samples were collected prior to and during treatment. Serum was separated and frozen prior to shipping. Over 100 samples were processed, among which some were repeatedly measured in order to determine the inter-day precision due to sample thawing. Activities of three commercially available drugs, E. coli-derived asparaginase or Erwinia chrysanthemi asparaginase or E.coli pegylated, PEG-asparaginase were measured in intervals as recommended. Laboratory measurements used plate reader-based indooxine method where L-aspartic beta-hydroxamate (AHA) was a substrate for the enzyme. The reading time was optimized to ensure the best results.

41 patients (38 ALL and 3 lymphoma cases) were included in the study. Among thirty native E. coli asparaginase-treated patients, three (10\%) of them developed an allergy and four (13\%) of them showed silent inactivation.

Patients without hypersensitivity to native drug had serum median trough levels of $281,3 \mathrm{U} / \mathrm{L}$ after $48 \mathrm{~h}$. Six patients were treated with Erwinia asparaginase; one developed an allergy and none silent inactivation while others had median through levels 90,3 U/L after $48 \mathrm{~h}$. The PEG asparaginase therapy was given to 4 patients where median trough decline was observed $(938,4 \mathrm{U} / \mathrm{L}, 479,5 \mathrm{U} / \mathrm{L}, 170,3 \mathrm{U} / \mathrm{L}$ for 7,14 or 21 days, respectively).

Serum samples were stabile after second thawing as were no significant difference in asparaginase level after re-testing. Additionally, the absorbance results showed no significant difference between the 10 minutes reading intervals.

Here we conclude that therapeutic drug monitoring is important for pediatric patients with hematological cancer. The spectrophotometric-based method showed precise performance and has been added to our routine clinical protocols.

\section{HAIRY POLYP OF THE NASOPHARYNX - THE IMPORTANCE OF TEAM WORK}

Jelena Roganovic*, Valkovic Zuic Petra, Velepic Marko, Roganovic Jelena. Clinical Hospital Centre Rijeka

10.1136/archdischild-2021-europaediatrics.318

Hairy polyps are rare benign congenital dermoid tumors consisting of both mesodermal and ectodermal elements. They appear as soft, fleshy, pedunculated masses typically located in nasopharynx or oropharynx, usually at birth or soon after birth. Clinical manifestations include respiratory distress, shortness of breath, cyanosis, and difficulties with oral intake. On histology, hairy polyps comprise an outer keratinizing squamous epithelium with adnexal tissue, including hair follicles, and central fibroadipose and cartilaginous tissue. The imaging of choice is magnetic resonance imaging (MRI). MRI is helpful in characterizing the lesions and providing preoperative diagnosis. Further, it delineates the site of origin of these lesions, which can facilitate surgical planning and exclude an intracranial component. This is of the major importance if trans-nasal approach with endoscopy is planned in order to avoid injury to critical structures, such as the internal carotid artery.

We present a case of a 6-week-old full-term female baby presented with intermittent upper airway obstruction. On otorhinolaryngologic examination, an oval, smooth mass was visible in the left side of oropharynx, appeared to descend from the lateral wall of nasopharynx. MRI revealed a lobular mass $10 \times 4.8 \mathrm{~mm}$ on the left nasopharynx, spanning from torus tubarius to pharyngeal recess. Four days later a complete surgical excision was performed. On histology the lesion demonstrated adnexal skin structures overlying mesenchymal tissue, comprised mostly of fat and cartilaginous nodules. Two smaller parts of $0.4 \mathrm{~cm}$ in diameter were covered with stratified squamous epithelium and consisted of muscle cells and seromucous glands. The findings were consistent with the hairy polyp. MRI repeated after 2 months was normal. At 1 year follow-up, the child is in a good condition and without breathing or oral intake difficulties.

This case emphasizes the importance of multidisciplinary approach in neonates with nasopharyngeal masses, in order to provide timely and accurate diagnosis as well as the optimal treatment. 